\title{
Numerical and experimental study on thermoelectric radiant panel heating operation
}

\author{
Hansol Lim ${ }^{1}$, Joon-Young Park ${ }^{1}$, Yoo-Suk Byon ${ }^{1}$, Yong-Kwon Kang ${ }^{1}$, Jae-Weon Jeong ${ }^{1}$ \\ ${ }^{1}$ Department of Architectural Engineering, Hanyang University, Seoul, Republic of Korea
}

\begin{abstract}
This study aims to investigate a principle and strategy for thermoelectric radiant panel (TERP) heating operation using numerical and experimental methods. A numerical simulation model for a TERP was developed based on the finite difference method. Additionally, a mock-up TERP model was constructed to validate the numerical model and define its operation strategy in the heating mode. The results revealed that the TERP can stably operate without fan operation by the Joule effect of the thermoelectric module (TEM). Moreover, the TERP in heating mode showed a lower coefficient of performance (COP) with fan operation when the outdoor air temperature was lower than approximately $23^{\circ} \mathrm{C}$. This is because the lower outdoor air temperature could not supply useful heat to the cold side of the TEM during heating. Therefore, it is recommended to use a TERP without fan operation for heating purposes.
\end{abstract}

\section{Introduction}

A thermoelectric module (TEM) is a solid-state heat pump which mainly operates based on the Peltier effect and Joule effect. The heat absorption and rejection are occurred at the cold and hot side of TEM at the same time when the direct current flows into the n- and p- type semiconductor in TEM. It has many advantages of compact size, no refrigerant, no moving parts without noise and vibration (Lim et al., 2018). Therefore, extensive research is being conducted on the application of TEMs in the heating, ventilation, and air conditioning (HVAC) systems of buildings (Shen et al., 2016). Among these, the thermoelectric radiant panel (TERP) has shown good feasibility as a parallel cooling and heating unit (Lim and Jeong, 2018).

There are water-cooled- (Lertsatithankorn et al., 2009) and air-cooled-type (Shen et al., 2017; Luo et al., 2017; Lim et al., 2018) TERPs for removing heat that is rejected during cooling operation. Specifically, the air-cooled type is attracting increased attention because of its simple structure and convenience. Thus far, research has primarily focused on cooling operation performance.

However, TERP can be used for heating by converting the direction of input direct current easily. Therefore it is necessary to investigate the heating performance and operation strategy for TERP.

In this study, a numerical model for TERP in heating operation was developed to investigate its heating performances and suitable operation strategy. For validation, the experiments were conducted to estimate its energy performance according to the condition of heat source (i.e. cold side of TEM).

\section{System overview}

A TERP consists of an aluminum panel (for radiant cooling and heating), insulation (to prevent unnecessary heat transfer between cold and hot sides), TEM, and heat sink, as shown in Fig. 1. In the present study, an air-cooled TERP is used. Therefore, outdoor air is used to remove heat from the hot side of the TEM in cooling mode (Fig. 2 ). Comparatively, the direction of heat absorption and rejection is converted in heating mode by changing the input current direction at the TEM. When using a fan in heating mode (Fig. 2a), heat from the outdoor air is absorbed by the cold side of the TEM. If the outdoor air temperature is high, the TEM can show a higher coefficient of performance (COP). However, outdoor air temperatures are generally low in the heating season. Therefore, fan operation would not be energy efficient. Hence, TERP heating without fan operation (Fig. 2b) is proposed, and its feasibility is examined based on heating and energy performance.

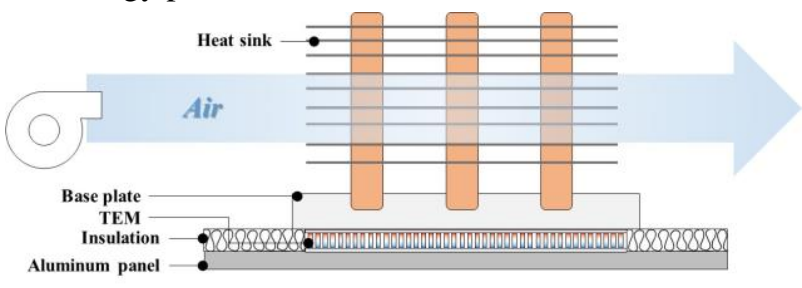

Figure 1: Section of thermoelectric radiant panel

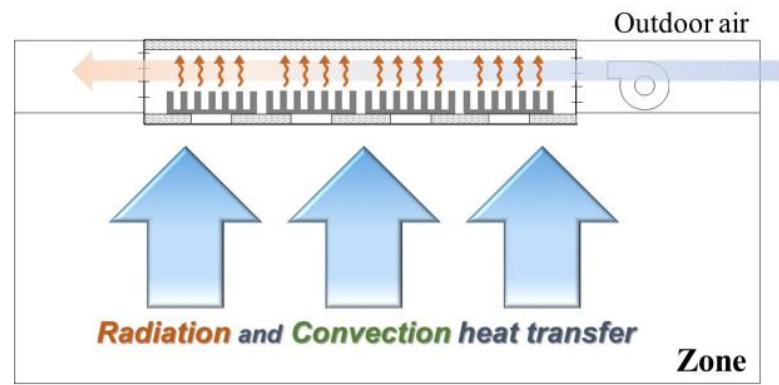

Figure 2: Thermoelectric radiant panel in cooling operation. 


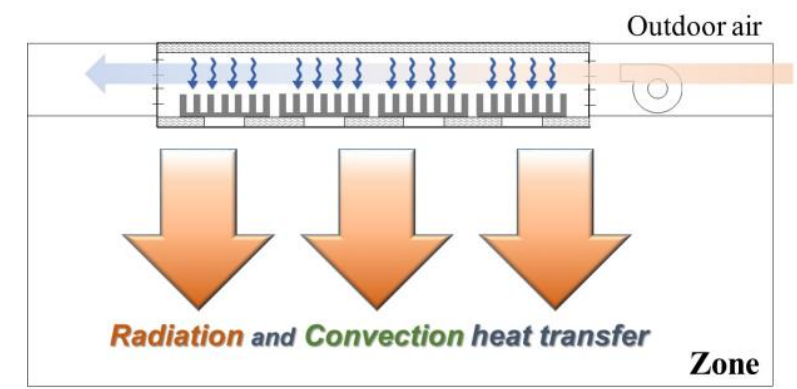

(a) With fan operation

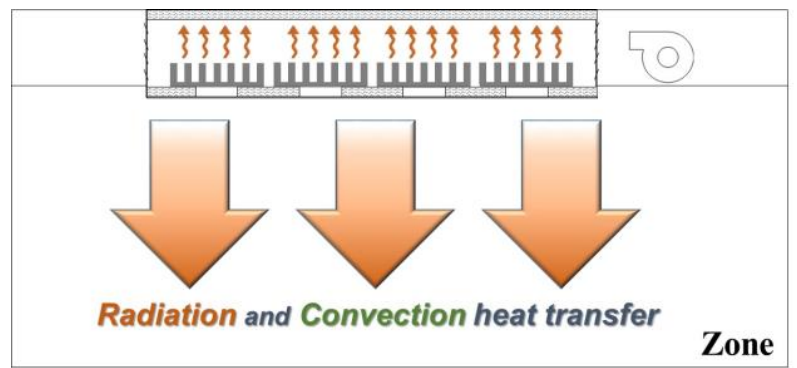

(b) Without fan operation

Figure 3: Thermoelectric radiant panel in heating operation.

\section{Simulation model}

A simulation model of a TERP operating in heating mode was developed to theoretically predict its behavior and understand its heating mechanism.

\section{Thermoelectric module model}

The TEM performance was simulated using the semiblack-box model from a previous study (Chen and Snyder, 2013). The thermo-physical properties of TEM, such as the Seebeck coefficient $(S)$, electrical resistivity $(R)$, and thermal conductivity $(K)$, were calculated using Eqs. (1) to (3) based on the technical specifications of the TEM (Table 1). The thermo-physical properties are varied according to the hot side temperature of TEM $\left(T_{h}\right)$.

$$
\begin{gathered}
S=\frac{2 Q_{\max }\left(T_{h}-\Delta T_{\max }\right)}{T_{h}^{2} I_{\max }} \\
R=\frac{2\left(T_{h}-\Delta T_{\max }\right)^{2}}{T_{h}^{2}} \frac{Q_{\text {max }}}{I_{\text {max }}^{2}} \\
K=\frac{\left(T_{h}-\Delta T_{\max }\right)^{2}}{T_{h}^{2}} \frac{Q_{\text {max }}}{\Delta T_{\max }}
\end{gathered}
$$

Table 1: Technical specifications of the TEM used in this study

\begin{tabular}{cc}
\hline Description & Value \\
\hline Maximum input current $\left(I_{\max }\right)$ & $6.4 \mathrm{~A}$ \\
Maximum input voltage $\left(V_{\max }\right)$ & $14.7 \mathrm{~V}$ \\
Maximum cooling capacity $\left(Q_{\max }\right)$ & $56 \mathrm{~W}$ \\
Maximum temperature difference between & $71^{\circ} \mathrm{C}$ \\
cold and hot side of TEM $\left(\Delta T_{\max }\right)$ & \\
\hline
\end{tabular}

\section{Convection and radiation coefficient}

At the surface of the radiant panel, heat is transferred by convection and radiation, which can be calculated in Eqs. (7) to (13) (Lim et al., 2018; Ostrach, 1953; Fuji and Imura, 1972; Cengel, 2007). The Reynolds number (Re) at the surface is calculated using the air density $\left(\rho_{\text {air }}\right)$, air velocity $\left(v_{\text {air }}\right)$, characteristic length of air $\left(L_{c}\right)$, and viscosity $(\mu)$ in Eq. (2). The characteristic length $\left(L_{c}\right)$ is defined as the length of the panel $\left(L_{\text {panel }}\right)$ when the external fluid is considered on the flat plate. Using the Reynolds number $(R e)$ and Prandtl number for air $(P r)$, the Nusselt number $(\mathrm{Nu})$ is calculated in Eq. (8). The Grashof number $(G r)$ is calculated in Eq. (9) using the acceleration of gravity $(g)$ and the coefficient of cubical expansion of air $(\beta)$. Subsequently, the Rayleigh number $(R a)$ is derived from Eq. (10), and the Nusselt number $(\mathrm{Nu})$ is determined in Eq. (11). Finally, the heat convection coefficient at the surface of the radiant panel can be determined using Eq. (12). All the equations in Eqs. (7) to (12) are from the condition that the external fluid under the cold flat plate.

$$
\begin{aligned}
& R e=\frac{\rho_{\text {air }} v_{\text {air }} L_{c}}{\mu} \\
& N u=\begin{array}{l}
0.664 \operatorname{Re}^{\frac{1}{2}} \operatorname{Pr}^{\frac{1}{3}}\left(\operatorname{Re}<5 \times 10^{5}\right) \\
0.037 \operatorname{Re}^{\frac{4}{5}} \operatorname{Pr}^{\frac{1}{3}}\left(\operatorname{Re} \geq 5 \times 10^{5}\right)
\end{array} \\
& G r=\frac{g \beta\left(T_{\text {surf }}-T_{\text {room }}\right) L_{c}{ }^{3}}{v_{\text {air }}{ }^{2}} \\
& R a=G r \times P r \\
& N u=0.27 R a^{1 / 4} \quad\left(10^{5}<R a<10^{11}\right) \\
& h_{\text {conv }}=\frac{\kappa_{a i r} N u}{L_{c}}
\end{aligned}
$$

The heat radiation coefficient is defined according to the emissivity of the radiant panel $(\varepsilon)$, Stefan-Boltzmann constant $(\sigma)$, mean radiant temperature $\left(T_{M R T}\right)$, and surface temperature of the radiant panel $\left(T_{\text {surf }}\right)$ in Eq. (13) (Cengel, 2007).

$$
h_{\text {rad }}=\varepsilon \sigma\left(T_{M R T}^{2}+T_{\text {surf }}^{2}\right)\left(T_{M R T}+T_{\text {surf }}\right)
$$

Consequently, the heating capacity of the panel with respect to the surface temperature can be derived in Eq. (14). The mean radiant temperature $\left(T_{M R T}\right)$ is assumed to be equal to the room temperature $\left(T_{\text {room }}\right)$ based on the previous experimental study (Walikewitz et al., 2015).

$$
Q_{\text {panel }}=\left(h_{\text {conv }}+h_{\text {rad }}\right) A_{\text {panel }}\left(T_{\text {surf }}-T_{\text {room }}\right)
$$

\section{Heat transfer model}

An analysis of the TERP was conducted using a twodimensional (2D) finite difference model in the crosssectional direction, as shown in Fig. 4. The TERP baseplate consists of three parts - the heat sink, TEM, and aluminum panel. Additionally, only half the area between the two TEMs was used to reduce the calculation time using a symmetric boundary condition owing to the symmetric geometry. Also, we used fixed boundary conditions at both sides: the duct air temperature $\left(T_{\text {duct }}\right)$ and the room air temperature $\left(T_{\text {room }}\right)$ to replicate the stable operation condition.

Heat is transferred between the duct air and the cold side of TEM by convection and conduction. Also, there are three heat transfers between the two sides of the TEM: First, heat is conducted from the hot to the cold side of the TEM by temperature difference; second, heat generated by the Joule effect is transferred to both the cold and hot sides of the TEM; and third, heat is transferred from the 


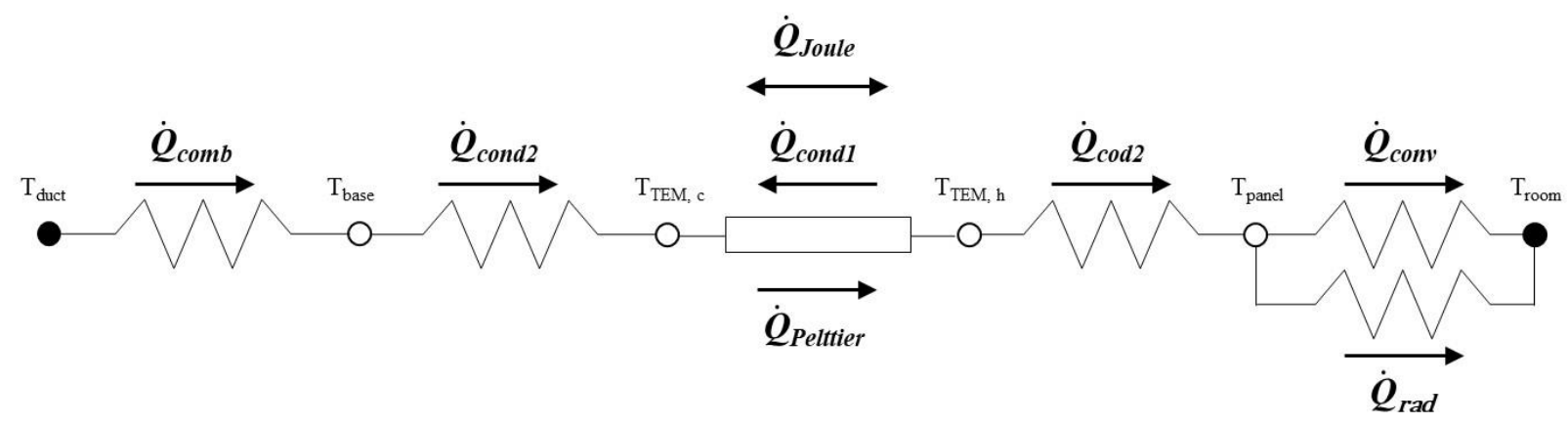

Figure 4: Illustration of the steady-state heat flows during TERP heating operation

cold to the hot side of the TEM by the Peltier effect. Additionally, heat is transferred from the hot side of the TEM to the air in the room. Each of these heat transfers were discretized using the finite difference method based on the energy balance.

\section{Laboratory experiments}

\section{Experiments overview}

A mock-up TERP model was constructed for experiments as shown in Fig. 5. Three TEMs were used and the size of the aluminum panel was $0.4 \mathrm{~m} \times 0.4 \mathrm{~m}$ with a $5 \mathrm{~mm}$ thickness. The height of each duct was $0.25 \mathrm{~m}$ and two transitions were used to connect flexible ducting for taking the conditioned air for heat removal from the environment chamber.

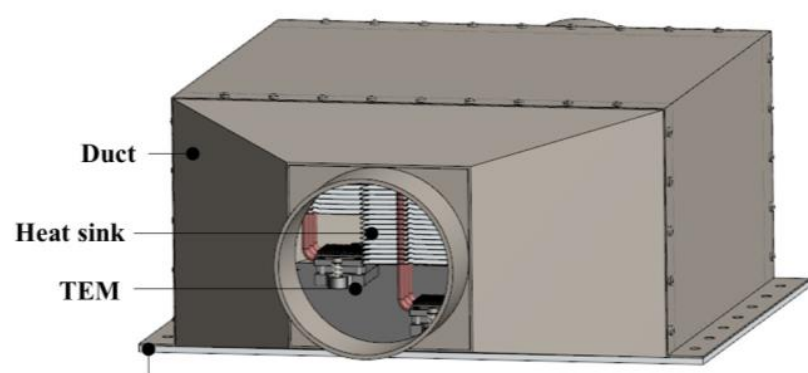

Radiant heating panel

(a) 3D model of TERP

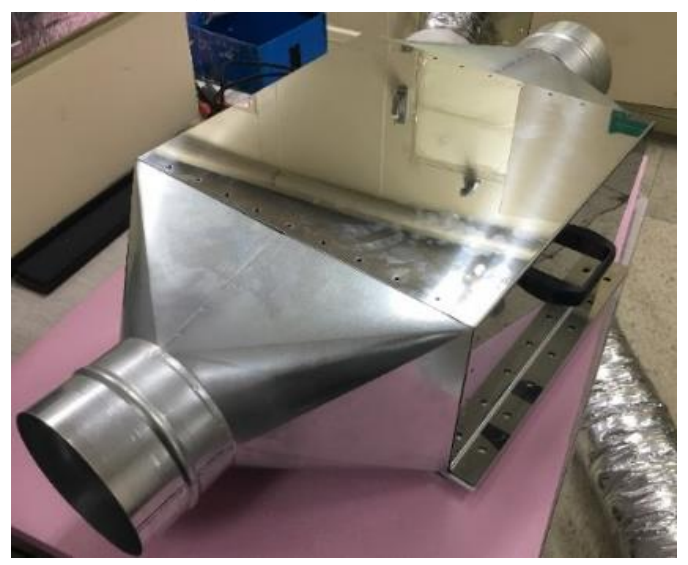

(b) Mock-up TERP model

Figure 5: 3D model and mock-up TERP model

In Fig. 6, the experiment setup is shown. The environment chamber was used to condition air according to the experiment cases. And a variable speed fan was used to draw conditioned air into the duct according to each experiment case. Additionally, a switched-mode power supply (SMPS) was used to control the input current and voltage to the TEM.

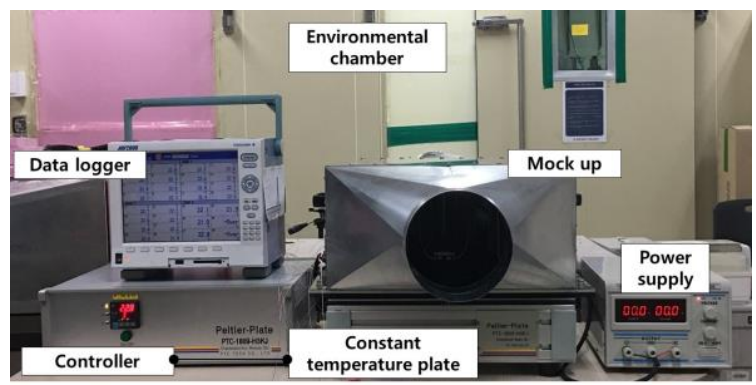

Figure 6: Setup for validation experiments

To duplicate the room temperature and heat transfer between the room and radiant panel, a constanttemperature plate was used (Klinker et al., 2014). The insulation was selected which has the same heat transfer coefficient with the calculated heat transfer coefficient between the room and radiant panel. It means that the convection and radiation heat transfer between room and the panel were substituted by heat conduction through insulation. Therefore, the selected insulation was inserted between the constant-temperature plate and radiant panel to meet the theoretical heat flux from the room to the panel. The temperature of the constant temperature plate was set as room temperature according to each experiment case by a controller. The arrangement of the experiment to duplicate the room temperature for TERP operation is described in Fig. 7. The surface temperatures at the cold side of the TEM (Point 1) and radiant panel (Point 2) were measured using T-type thermocouples and validated with a data logger.

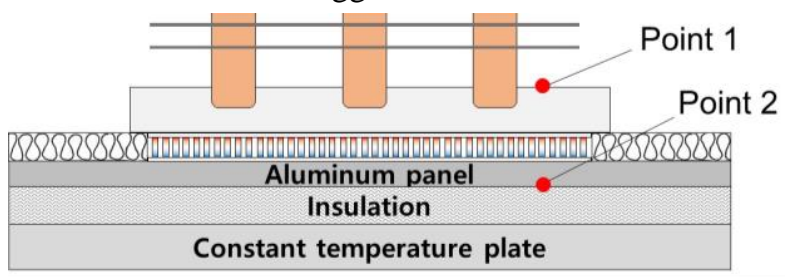

Figure 7: Arrangement of experiment and measurement points 


\section{Validation experiments}

A numerical simulation was conducted to investigate the thermal behavior of the TERP in heating mode without fan operation. The simulation time was set to $30 \mathrm{~min}$ to reach stable surface temperature and two simulation cases were conducted at surface temperatures of $45^{\circ} \mathrm{C}$ and $60^{\circ} \mathrm{C}$. The duct air temperature was set to be $26^{\circ} \mathrm{C}$ and the room air temperature was $24^{\circ} \mathrm{C}$.

As shown in Fig. 8, 2D contours for cross-sections of the TERP were plotted by temperature. The results showed that a high surface temperature was well-maintained without fan operation, regardless of the target surface temperature. Additionally, the cold-side temperature was determined by the duct air temperature.

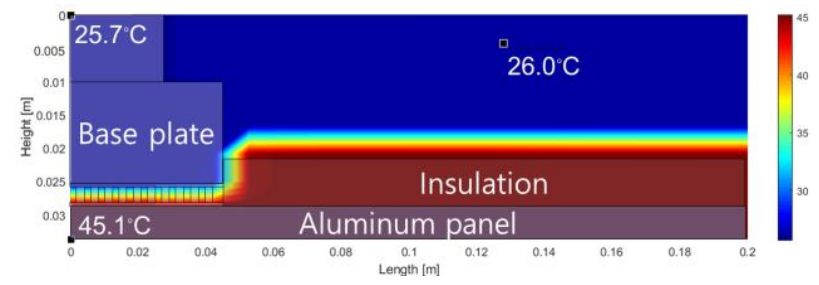

(a) $T_{\text {surf }}=45^{\circ} \mathrm{C}$

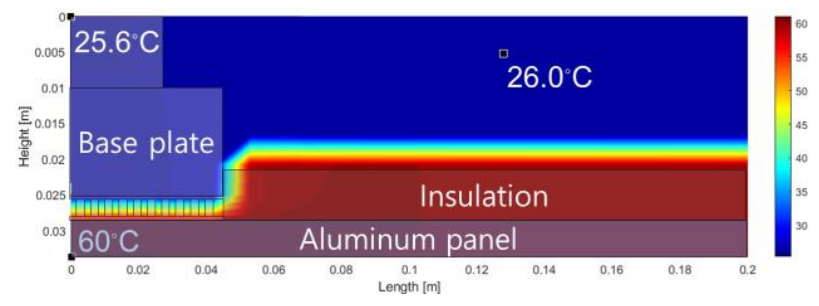

(b) $T_{\text {surf }}=60^{\circ} \mathrm{C}$

Figure 8: Simulation results for TERP in heating mode

Validation experiments were conducted under the same conditions as the numerical simulation. As shown in Fig. 9, temperatures measured at the surface and at the cold side of the TEM were plotted in the time domain after the surface temperature met the target value.

The results showed that the TERP maintained the target heating temperature without fan operation in stable condition. The cold-side temperature showed a value similar to the duct air temperature, which indicates that the thermal behavior predicted by the numerical model was in good agreement within $2.3 \%$ and $8.6 \%$ error rate when the surface temperature was $45^{\circ} \mathrm{C}$ and $60^{\circ} \mathrm{C}$, respectively. The difference was that the duct air temperature increased slightly during operation because the insulation did not provide the ideal heat transfer prevention between the radiant panel and duct.

Therefore, we can conclude that the TERP can operate in heating mode without fan operation. This is because the heating mechanism of the TEM consists of the Peltier effect, Joule effect, and heat conduction, however the joule effect can mainly work for heating operation without a heat source from the air side.

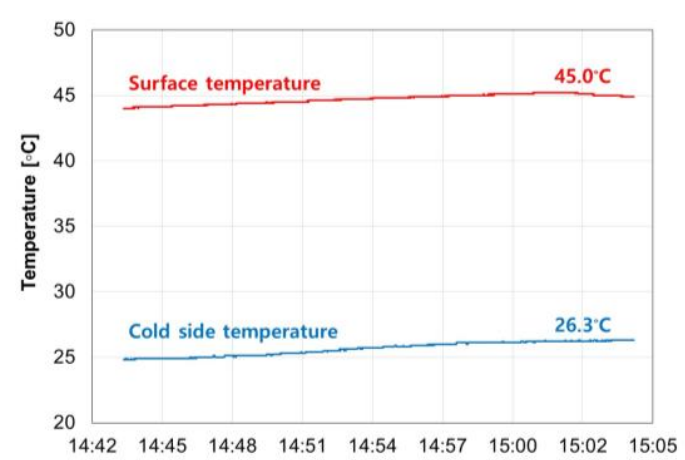

(a) $T_{\text {surf }}=45^{\circ} \mathrm{C}$

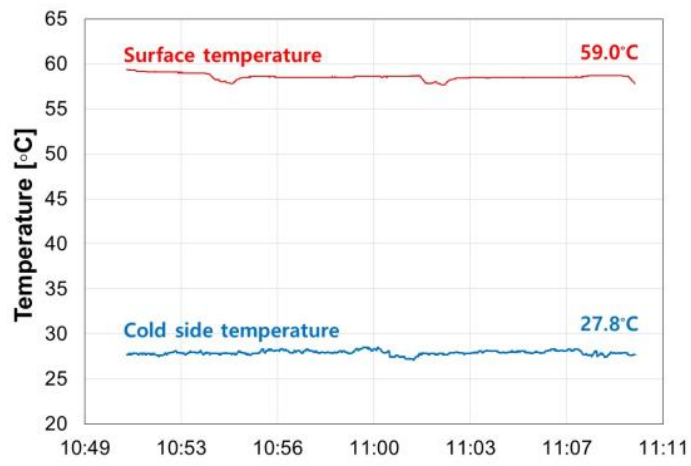

(b) $T_{\text {surf }}=60^{\circ} \mathrm{C}$

Figure 9: Experiment results for TERP in heating mode Necessity of fan operation

To examine the necessity of fan operation during heating with the TERP, experiments were conducted according to the surface temperature, air flow rate, and air temperature. The experiment cases are summarized in Table 2. The range of air temperature $\left(T_{O A}\right)$ was determined as wide as possible based on the environment chamber capacity. For heating purpose, the outdoor air higher than room temperature is unnecessary in fact, however it was also used for experiments to investigate the performance of TERP in heating operations. The volume air flow rate $\left(\dot{V}_{O A}\right)$ was determined based on a previous study (Lim et al., 2018). In the experiments, power consumption was measured and compared for cases with and without fan operation.

Table 2: Experiment cases to examine the necessity of fan operation

\begin{tabular}{cccc}
\hline Case & $\mathrm{T}_{\text {surf }}\left[{ }^{\circ} \mathrm{C}\right]$ & $\dot{V}_{O A}\left[\mathrm{~m}^{3} / \mathrm{h}\right]$ & $\mathrm{T}_{\mathrm{OA}}\left[{ }^{\circ} \mathrm{C}\right]$ \\
\hline 1 & 45 & - & - \\
2 & 45 & 50 & 8 \\
3 & 45 & 400 & 8 \\
4 & 45 & 50 & 36 \\
5 & 45 & 400 & 36 \\
\hline 6 & 60 & - & - \\
7 & 60 & 50 & 8 \\
8 & 60 & 400 & 8 \\
9 & 60 & 50 & 36 \\
10 & 60 & 400 & 36 \\
\hline
\end{tabular}


In Fig. 10, the power consumption of the TERP without fan operation was $80.1 \mathrm{~W}$ and $227.9 \mathrm{~W}$ when the surface temperature was $45^{\circ} \mathrm{C}$ and $60^{\circ} \mathrm{C}$, respectively. Furthermore, the COP of the TERP without fan operation was 1.24 and 0.92 for the surface temperature of $45^{\circ} \mathrm{C}$ and $60^{\circ} \mathrm{C}$, respectively. While the air volume flow rate and temperature each made a difference, the latter was more significant.

Additionally, the results indicated that it was unnecessary to operate the fan when the outdoor air temperature was below $28.4^{\circ} \mathrm{C}$ in all cases, based on the linear regression model. The critical temperature for fan operation varied according to the target heating surface temperature and air volume flow rate, However, not all critical outdoor air temperatures exist during the heating season.

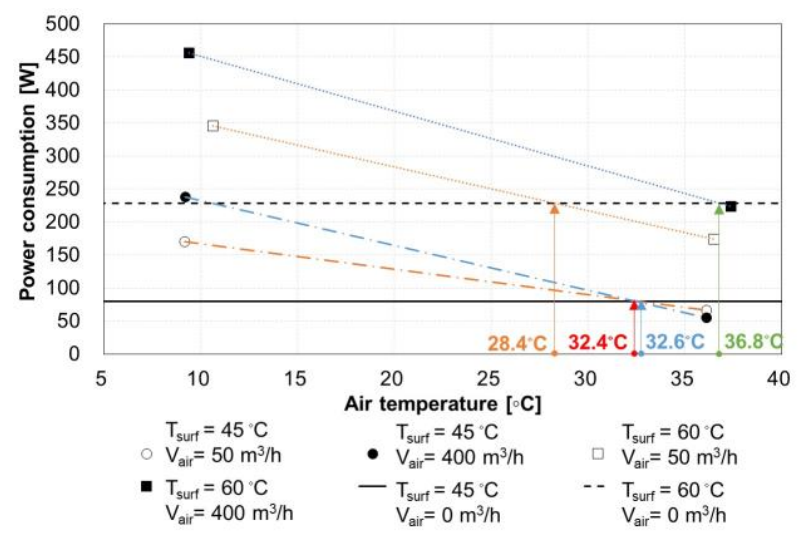

(a) Power consumption

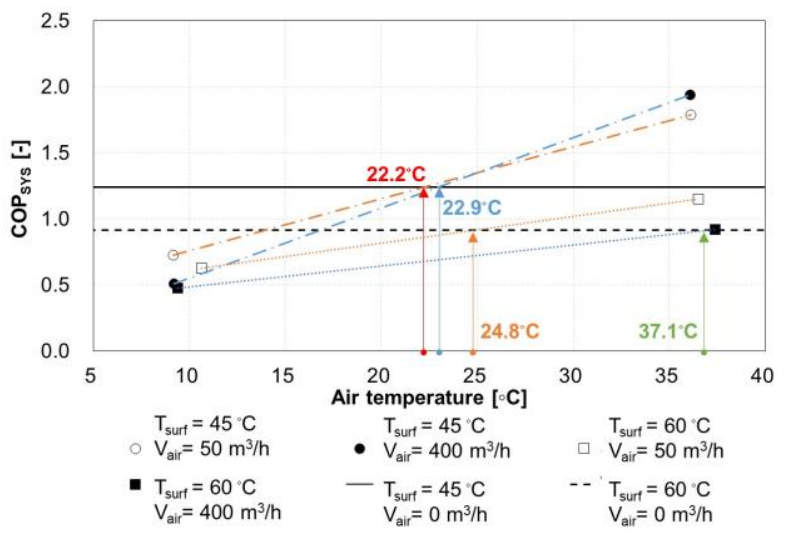

(b) COP of system

Figure 10: Experiment results for TERP in heating mode

\section{Summary and conclusions}

In this study, the thermal behavior of a TERP used in heating mode was investigated using a numerical model and experiments. The results showed that the TERP can be operated in heating mode without fan operationdifferent from cooling mode-owing to the Joule effect of the TEM. When outdoor air temperatures are higher than $28.4^{\circ} \mathrm{C}$, the TERP may consume less energy for heating with fan operation than without. However, there is no such period in practical situations. Therefore, it can be concluded that fan operation is not needed during heating with a TERP.
Before this finding, the TERP was only studied for cooling purpose, however it can be used for heating in the building. In the future, the empirical models will be developed to predict its heating capacity and energy consumption.

\section{Acknowledgement}

This work was supported by the Korean Agency for Infrastructure Technology Advancement (KAIA) grants (19CTAP-C141826-02), by the Korean Institute of Energy Technology Evaluation and Planning (KETEP) (No. 20184010201710), and by the National Research Foundation of Korea (NRF) grant (No.2019R1A2C2002514).

\section{References}

Cengel, Y. A. (2007). Heat and Mass Transfer: Fundamentals and Applications ( $3^{\text {rd }}$ edition). McGraw-Hill, New York, Boston.

Fuji, T., Imura, H. (1972). Natural-convection heat transfer from a plate with arbitrary inclination. International journal of heat and mass transfer 15 , 755-767.

Klinker, F., Konstantinidou, C., Mehling, H., Weinläder, H. (2014), Dynamic Thermal Behaviour of Two Newly Developed PCM Cooling Ceiling Prototypes. EuroSun conference. Aixles-Bains (France).

Lertsatitthanakorn, C., Wiset, L., Atthajariyakul, S. (2009). Evaluation of the thermal comfort of a thermoelectric ceiling cooling panel (TE-CCP) system. Journal of electronic materials 38, 1472-1477.

Lim, H., Cheon, S. Y., Jeong, J. W. (2018). Empirical analysis for the heat exchange effectiveness of a thermoelectric liquid cooling and heating unit. Energies 11, 580-583.

Lim, H., Jeong, J. W. (2018). Energy saving potential of thermoelectric radiant cooling panels with a dedicated outdoor air system. Energy and buildings 169, 353365.

Lim, H., Kang, Y. K., Jeong, J. W. (2018). Thermoelectric radiant cooling panel design: Numerical simulation and experimental validation. Applied thermal engineering 144, 248-261.

Luo, Y., Zhang, L., Liu, Z., Wu, J., Zhang, Y., Wu, Z. (2017). Three-dimensional temperature field of thermoelectric radiant panel system: Analytical modeling and experimental validation. International journal of heat and mass transfer 114, 169-186.

Ostrach, S. (1952). An analysis of laminar freeconvection flow and heat transfer about a flat plate parallel to the direction of the generating body force (No. NACA-TN-2635). National Aeronautics and Space Administration Cleveland Oh Lewis Research Center.

Shen, L., Pu, X., Sun, Y., Chen, J. (2016). A study on thermoelectric technology application in net zero energy buildings. Energy 113, 9-24. 
Shen, L., Tu, Z., Hu, Q., Tao, C., Chen, H. (2017). The optimization design and parametric study of thermoelectric radiant cooling and heating panel. Applied thermal engineering 112, 688-697.
Walikewitz, N., Jänicke, B., Langner, M., Meier, F., Endlicher, W. (2015). The difference between the mean radiant temperature and the air temperature within indoor environments: A case study during summer conditions. Build Environ 84, 151-161. 